\title{
Editorial
}

\section{MolBank: What Is It Good for?}

\section{Norbert Haider}

Department of Drug and Natural Product Synthsesis, University of Vienna, Althanstraße 14, A-1090 Vienna, Austria

E-mail: norbert.haider@univie.ac.at

Received: 14 January 2009 / Published: 15 January 2009

From time to time, the Publisher and the Editor-in-Chief of MolBank are asked the question: "what is the purpose of publishing a journal like MolBank?" We think that the start of a new year is a good opportunity to make the ideas behind such a journal as clear as possible to our readers, authors and reviewers. In principle, the answer to this question might be boiled down to a single term: "usefulness". But allow me to go a little bit more into detail.

The main purpose and scope of MolBank as one of MDPI's Open Access journals is clearly defined on its website as an electronic journal for the rapid publication of very short communications, typically one compound per paper. The aim of this policy is to save potentially useful scientific information from being lost. In many research groups, there are unpublished compounds stored somewhere on the shelf (or in the refrigerator) which do not really fit into a full paper, e.g. because the main work in this series has already been published. Nevertheless, somebody else might be interested just in this particular compound, be it for comparison of physicochemical data or spectral properties, biological testing, etc. From my own experience as a medicinal chemist, I know that such scattered material in many cases would never be published (despite full characterisation of the compound in question) and thus the information would be lost sooner or later.

It is obvious that a typical MolBank short communication has lower scientific "value" than a full paper or a classical short paper in one of the well-established journals and that such a paper is not very relevant for academic promotion of its author. But as explained above, we think that MolBank has its little niche on the market. Published articles are abstracted by Chemical Abstracts and, last but not least, MolBank helps to populate MDPI's collection of deposited compound samples. The latter collection, in turn, has also been found quite useful by a number of researchers around the world. After all, I think that "usefulness" to the scientific community is still a relevant aspect in today's world of permanent evaluation, ranking, and impact-factor-counting. 
Just to be clear: this journal profile does not conflict with the principle of quality. All submissions undergo a careful peer-review process and are accepted for publication only if they really meet our criteria of scientific quality and soundness. Whereas nobody expects articles describing groundbreaking discoveries in MolBank (although they are always welcome, of course), a certain level of novelty must be inherent. All relevant literature must be carefully cited, experimental procedures must be clear and reproducible, all new compounds must be adequately characterised, and the overall quality of the manuscript (including chemical nomenclature, graphical presentation, language, etc.) must be appropriate. Quality and usefulness are not contradictory concepts.

After some restructuring and reinforcement of the Editorial Office in 2008, we are quite confident that MolBank will continue to serve its community of readers, authors and reviewers in an efficient and truly useful way. My best wishes for 2009 to all of you!

Norbert Haider. Ph.D.

Editor-in-Chief of Molbank

(C) 2009 by Molecular Diversity Preservation International, Basel, Switzerland. This article is an openaccess article distributed under the terms and conditions of the Creative Commons Attribution license (http://creativecommons.org/licenses/by/3.0/). 